dentally tend to favour the latter view, with the result that in the process of confirming the UGDP results on tolbutamide the FDA has seemed to its critics to be cutting across a vexed and as yet unresolved academic controversy.

Dr Robert Bradley of the Joslin Clinic, who helped draft the statement criticizing the FDA, believes along with other doctors that the agency has gone too far in extrapolating the results of the UGDP survey from patients not dependent on insulin, who were the sub. jects of the survey, to all kinds of diabetics. The agency also seems to have taken a more definite vicw of the toxicity of tolbutamide than the AMA Council on Drugs felt was justifiable. The council in its statement said only that tolbutamide "may have played a "toxic" role with respect to cardiovascular mortality" but that this interpretation "is quite difficult and may or may not be valid".

Adding to the bad feeling between the agency and the medical community is the series of press leaks, both in this and previous instances, that have alarmed the public and made quick decisions necessary. The AMA at its annual convention in June this year went out of its way to reprove the FDA for its news policies which had "created undue anxiety" among diabetics. According to the November 2 issue of the AMA's newsletter, American Medical News, the agency also failed to prepare its bulletin on tolbutamide by the deadline agreed with the AMA and the American Diabetes Association, according to which all three organizations would release statements at the same time. The plan also called for the publication of the full article in October, now not expected until the end of this month.

The fact that the UGDP report is still unpublished seems much to blame for the bickering and backbiting that now surround discussion of the survey and may cling to it for some time to come. Why could the FDA not have waited until the full report was out? "The political pressures are too great to withstand," an FDA official explained last week - "the medical profession always chides the agency as premature when it acts promptly and it is pilloried by Congress and in the press if it bides its time." But if the Food and Drug Administration does not stand up to political pressures in order to allow scientific procedures due process, how is a rational decision to be arrived at? "You must ask Congress that," the official said.

\section{COOPERATION}

\section{Brighter Outlook for Astronauts}

\section{by our Astronomy Correspondent}

ONE of the ways in which 1970 has been a remarkable year is that cooperation between the United States and the Soviet Union in space exploration has at last seemed a possibility, although a remote one. Nature has already chronicled the long history of attempts at collaboration $(225,1094 ; 1970)$ and, whatever the rcasons, the tale is depressing. But this autumn, almost out of the blue, moves towards cooperation took place whose outcome so far has, for once, not been disheartening.

Nobody knows what part the near-disaster of Apollo 13 played in the prehistory of the present negotiations with the Soviet Union. But the notion that there could be some kind of standardization of systems allowing

Soviet spacecraft to dock with those of NASA and vice versa surfaced at the autumn congress of the International Astronautical Federation (see Nature, 228, $198 ; 1970)$. After that the talks progressed remarkably quickly, and the fact that an agreement had been reached between NASA and the Academy of Sciences of the USSR was announced on October 29. On the Soviet side of the talks held in Moscow were B. N. Petrov, K. P. Feoktistov, V. S. Syromyatnikov, V. V. Suslennikov and V. A. Lavrov, and on the American side Robert R. Gilruth, Arnold W. Frutkin, George B. Hardy, Caldwell C. Johnson, and Glynn S. Lunney. Now that the agreement has been confirmed by an exchange of notes between the acting administrator of NASA, Dr George Low, and the president of the Soviet Academy, Academician M. V. Keldysh, the text has been made available.

During the talks, which appear to have been limited to the question of compatibility of rendezvous and docking systems, the two sides exchanged information about their existing methods, and decided on twelve topics which merit further study:

(1) Passive reflectors of the radio guidance systems, their location and characteristics.

(2) Passive reflectors of the optical guidance system, their location and characteristics.

\title{
Apollo 14 Timetable
}

NASA has now published the preliminary timetable for the Apollo 14 mission, which will leave on January 31 for the Fra Mauro formation. All times are in BST.

Event

Launch from Cape Kennedy

Leave Earth orbit

Leave free-return trajectory

Lunar orbit insertion $(57 \times 170$ nautical miles)

Descent orbit insertion of docked spacecraft $(10 \times 58$ nautical miles)

Lunar module undocks and separates from spacecraft

Command/service module moves into circular orbit $(56 \times 63$ naut. ical miles)

Lunar module powered descent to lunar surface

Landing at lat. $3^{\circ} 40^{\prime} 19^{\prime \prime} \mathrm{S}$. , long. $17^{\circ} 29^{\prime} 46^{\prime \prime} \mathrm{W}$. the two astronauts will stay about 34 hours on the surface.

Begin 4 to 5 hours of lunar surface activity (EVA)

Begin second 4 to 5 hours of lunar surface activity

Liftoff of lunar module from Moon

Docking with command/service module

Lunar module jettisoned on to lunar surface

Apollo 14 leaves lunar orbit

Splashdown in Pacific Ocean for recovery by USS New Orleans
Date/time (BST)

Jan. 31, 9.23 p.m.

Jan. 31, 11.54 p.m.

Feb. 2, 3.59 a.m.

Feb. 4, 7.58 a.m.

Feb. 4, 12.17 p.m.

Feb. 5, 5.47 a.m.

Feb. 5, 7.07 a.m.

Feb. 5, 10.02 a.m.

Feb. 5, 10.14 a.m.

Feb. 5, 2.50 p.m.

Feb. 6, 11.30 a.m.

Fob. 6, 7.44 p.m.

Feb. 6, 9.30 p.m.

Feb. 6, 11.43 p.m.

Feb. 7, 2.35 a.m.

Fcb. 9, 10.01 p.m. 